\title{
Genetic and Environmental Influences on the Associations Between Attention Problems and Other Problem Behaviors
}

\author{
Stephanie Schmitz' and David A. Mrazek ${ }^{2}$ \\ 'Institute for Behavioral Genetics, University of Colorado, Boulder \\ ${ }^{2}$ The Mayo Clinic, Rochester, MN
}

\begin{abstract}
Problem behavior in children shows a high degree of cooccurrence, both within the domains of internalizing and externalizing behaviors and across domains. Maternal ratings of 207 same- and opposite-sex twin pairs on the Child Behavior Checklist (CBCL/4-18; Achenbach, 1991) were used to determine the etiology of these associations. In the current sample of 4- to 11-year-old children (mean age: 7.6 years) phenotypic correlations were 68 between Internalizing and Externalizing, between .41 and .66 within the internalizing scales, and between .58 and .71 within the externalizing scales. Correlations across domains on the scale level were of similar magnitude. Genetic and shared environmental correlations were generally high, with the exception of the somatic complaints scale which showed low genetic correlations with other scales. These findings of uniformly high shared etiology was seen within and across domains. For example, Attention Problems showed genetic correlations of .65 with Delinquent Behavior and .76 with Aggressive Behavior; the genetic correlations of Attention Problems with internalizing scales were .71 for Anxious/Depressed and .79 for Withdrawn; a low genetic correlation was only shown for the Somatic Complaints scale $\left(r_{g}=.16\right)$. Although the magnitude of shared environmental contributions was lower, the environmental correlations were close to unity, indicating that the same family environmental factors were involved in aspects of problem behavior when assessed across domains. Results for the Attention Problems scale were similar to other disruptive behavior, justifying its inclusion with the externalizing scales.
\end{abstract}

During the history of behavior genetics, research was initially conducted into the etiology of specific childhood behavior problems, that is, how much of individual variation is due to genetic and environmental influences on one particular behavior; for example, Deater-Deckard and Plomin (1999) reported for 7- to 12-year-olds that genetic influences accounted for $65 \%$ of the variation in externalizing, with a marked difference between delinquent (39\%) and aggressive behaviors (70\%). For seven-year-old twins, van der Falk et al. (submitted) reported individual variation due to genetic influences of 35\% for internalizing and 65\% for externalizing behaviors. However, the focus has recently shifted towards the co-variation between problem behaviors, recognizing the high degree of co-occurrence between them.

Exploring associations between behaviors within the same domain, Eley (1997) reported that the observed correlations of .60 between aggressive and delinquent behavior and of .30 between anxiety and depression symptoms were mainly accounted for by genetic factors common to each of the two behaviors. The phenotypic correlation between delinquent and aggressive behaviors as reported by DeaterDeckard and Plomin (1999) was also reported to be fairly high $(r=.70)$.

Particular interest has been placed in recent years on the co-occurrence of behaviors from the internalizing and externalizing domains which are not independent but highly correlated, both on the level of broadband groupings and of individual problem behaviors. For example, August et al. (1996) demonstrated both internalizing and externalizing behaviors were associated with Attention-Deficit/ Hyperactivity Disorder (ADHD). Eiraldi et al. (1997) reported that the co-occurrence between $\mathrm{ADHD}$ and other problem behavior depended on the ADHD subtype; internalizing problems were associated with both the inattentive and combined types while externalizing problems occurred more frequently with the combined type. Gabel et al. (1996) found that the degree of comorbidity was related to the severity of the hyperactivity problems themselves.

O'Connor et al. (1998), exploring the etiology of cooccurrence between depressive symptoms, an internalizing problem behavior, and antisocial behavior, an externalizing one, reported that $45 \%$ of the observed covariation between these symptoms was explained by a common genetic liability. However, Gjone and Stevenson (1997) found that the covariance between internalizing and externalizing behaviors in their sample accounted for by common environmental components was more important, particularly for five- to nine-year children. The age differences between the two samples (age 10-18 for O'Connor et al. (1998) and ages 5-15 for Gjone and Stevenson (1997)) might account for the differences in results, since genetic influences tend to increase with age (see e.g., Schmitz et al., 1995), on corresponding scales of the CBCL/2-3 and the CBCL/4-18). Using data from three-year-old twins, van den Oord et al. (2000) reported shared environmental correlations that were slightly higher than genetic correlations;

Address for correspodence: Stephanie Schmitz, Institute for Behavioral Genetics, Campus Box 447, University of Colorado, Boulder, CO 80309-0447, U.S.A. Email: schmitzs@ colorado.edu 
while nearly $39 \%$ of the phenotypic correlations between the CBCL scales were due to genetic influences, shared environmental factors accounted for over $50 \%$ of the observed variance.

For the current study we will analyze maternal behavior ratings of their twins between the ages of 4 to 11 years. We expect to replicate the moderate to high correlations between aspects of problem behavior. As our sample is slightly younger than Gjone and Stevenson's (1997), we expect both environmental and genetic factors to account for these associations. Additionally, we will test the associations between Attention Problems, a scale subsumed neither under the internalizing nor externalizing broadband grouping, and other aspects of problem behavior.

\section{Methods \\ Sample}

In cooperation with the Colorado Department of Health Statistics, all parents of twins were contacted by an informational letter during the mid - to late 1980's, when their children were infants. The response rate to this community based mailing was between 50 and 60\%. After 1986, continued recruiting for this sample increased mainly the numbers of opposite-sex twin pairs, as parents of same-sex pairs decided to participate in other longitudinal twin studies conducted at the Institute for Behavioral Genetics (IBG), University of Colorado, Boulder. Parents who had participated during the initial phase of this twin registry were contacted again in 1992/3 to collect data on their now school-aged children. Due to relocations, both within and out of the state, not all parents could be recontacted.

This sample consisted of 207 twin pairs of which 66 were monozygotic (MZ), 45 were dizygotic of the same sex (DZSS) and 96 dizygotic opposite sexed pairs (DZOS). The mean age was 7 years and 7 months (ranging from 3 years and 9 months to 11 years). Slightly more than half of the sample $(52.3 \%)$ were girls. In general, this was a white middle class sample, characteristic of the state's population.

Zygosity was determined using a questionnaire which had been developed based on the diagnostic rules by Nichols and Bilbro (1966). If the mother's opinion on her twins' zygosity changed from the first to the second evaluation, then these cases were either excluded from the analyses or reclassified for both time points based on the detailed questionnaire, following the criteria outlined by Goldsmith (1991).

\section{Materials and Methods}

The 1991 revision of the Child Behavior Checklist (CBCL/4-18; Achenbach, 1991) shows eight dimensions of problem behavior (Withdrawn, Somatic Complaints, Anxious/Depressed, Social Problems, Thought Problems, Attention Problems, Delinquent Behavior, Aggressive Behavior). The first three scales are combined into the Internalizing broadband grouping while the last two make up the Externalizing broadband grouping. All CBCL/4-18 items are summed up for the Total Problems score.

The children's mother was asked to complete a set of questionnaires, including the CBCL/4-18, first for one twin, then for the other. For the current study we chose the two broadband groupings and the scales that constitute them, with an emphasis on externalizing behaviors. Even though Attention Problems are not subsumed under a broadband grouping in this version of the CBCL, it is often considered an externalizing behavior and was thus included in the analyses.

\section{Analyses}

Estimates of the relative size of genetic and environmental influences on problem behaviors can be provided when twin data are used, with methods developed in the domain of quantitative behavioral genetics. These methods are based on the partitioning of observed, that is, phenotypic, variance into genetic and environmental components through the analysis of either correlation or covariance matrices. Review papers (LaBuda et al., 1993; Martin et al., 1997; Rutter et al., 1990) summarized these explorations of behavioral problems through twin studies and their usefulness in being able to separate genetic and environmental influences.

To estimate formally the genetic and environmental influences on children's problem behavior as assessed by the CBCL/4-18, structural equation modeling using covariance matrices was applied (Mx; Neale, 1997). Phenotypic variances result from influences from genes (A) as well as the shared and non-shared environment ( $\mathrm{C}$ and $\mathrm{E})$. This model compares $\mathrm{MZ}$ twin covariances with DZ twin covariances, given a genotypic correlation of 1.0 for $M Z$ twins (all genes are shared) or 0.5 for DZ twins (on average, half the segregating genes are shared). Based on this model, correlations that are higher for $\mathrm{MZ}$ than $\mathrm{DZ}$ twins would indicate genetic influences, since the only difference in the expected correlations between members of an $\mathrm{MZ}$ pair and those of a DZ pair is the greater genotypic correlation for identical twins. Bivariate Cholesky models were applied to combinations of behavioral data.

Figure 1 shows a bi-variate Cholesky model in which the paths from the common factors to the phenotype for ratings of one behavior $\left(h_{11}, c_{11}, e_{11}\right)$ indicate the relative magnitude of genetic and environmental influences on that aspect of problem behavior. The proportion of variance

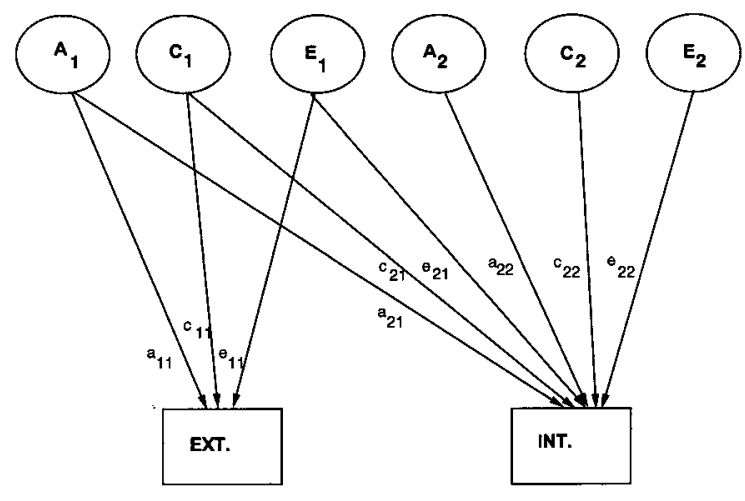

Figure 1

Bi-variate Cholesky model for aspects of internalizing and externalizing problem behaviors. 


\section{Table 1}

Means and Standard Deviations for CBCL/4 - 18 Raw Scores, by Zygosity

\begin{tabular}{lccc}
\hline Scale & DZ twins & MZ twins & $\begin{array}{c}\text { Norm Sample } \\
N=275\end{array}$ \\
& $N=132$ & $N=582 \mathrm{M} / 619 \mathrm{~F}$ \\
\hline Withdrawn & $1.8 \pm 1.8$ & $2.0 \pm 2.3$ & $1.8 / 2.0$ \\
Somatic Complaints & $0.9 \pm 1.5$ & $1.0 \pm 1.5$ & $0.8 / 1.0$ \\
Anxious/depressed & $2.8 \pm 2.7$ & $3.1 \pm 3.4$ & $3.1 / 3.4$ \\
Attention & $2.6 \pm 2.8$ & $2.6 \pm 3.3$ & $3.3 / 2.5$ \\
Delinquent & $1.4 \pm 1.5$ & $1.5 \pm 2.0$ & $1.6 / 1.2$ \\
Aggressive & $7.0 \pm 5.5$ & $6.7 \pm 6.4$ & $8.2 / 7.0$ \\
Internalizing & $5.3 \pm 4.7$ & $5.9 \pm 5.9$ & $5.5 / 6.3$ \\
Externalizing & $8.3 \pm 6.7$ & $8.2 \pm 8.0$ & $9.8 / 8.2$ \\
\hline
\end{tabular}

Note: ${ }^{a}$ Achenbach, 1991

that is due to genetic or environmental influences (i.e., $h^{2}$, $\left.c^{2}, e^{2}\right)$ is obtained by squaring these path coefficients. The paths from the common factors to the phenotype of the second behavior $\left(h_{21}, c_{21}, e_{21}\right)$ indicate the extent to which genetic and environmental influences are common between the two behaviors. The paths from the three unique factors to the phenotype of the second behavior $\left(b_{22}, c_{22}, e_{22}\right)$ represent genetic and environmental influences that are new and thus independent of those operating on the first aspect of CBCL/4-18 assessed behavior.

\section{Results}

Table 1 shows the means and standard deviations for the CBCL/4-18 scales used in this study for $\mathrm{MZ}$ and DZ twins and the means from Achenbach's (1991) norm sample. CBCL/4-18 scores showed a skewed distribution and thus were transformed for subsequent analyses. Data for boys and girls were combined, since previous analyses had shown that at these ages the etiology of problem behavior did not differ by sex (Schmitz et al., 1995).

Means for MZ and DZ twins do not differ significantly from each other and are well within the normal range.

\section{Table 2}

Variance Components of CBCL/4 - 18 Scales

\begin{tabular}{llll}
\hline & $h^{2}$ & $c^{2}$ & $e^{2}$ \\
\hline Withdrawn & .23 & .23 & .54 \\
Somatic & $.35^{*}$ & .12 & .53 \\
Anxious & $.45^{* *}$ & .20 & .35 \\
Attention & $.54^{* *}$ & .07 & .39 \\
Delinquent & $.67^{* * *}$ & .07 & .26 \\
Aggressive & $.58^{* * *}$ & .15 & .27 \\
\hline Internalizing & $.33^{* *}$ & $.30^{*}$ & .38 \\
Externalizing & $.53^{* * *}$ & $.25^{*}$ & .22 \\
\hline
\end{tabular}

Note: $h^{2}$ denotes the variance component that is due to additive genetic influences, $c^{2}$ are those due to the shared environment, and $e^{2}$ are those components due to non-shared environmental influences. Parameter estimates are significant at the .05 level $\left({ }^{*}\right)$, the ,.01 level $\left(^{* *}\right)$, or .001 level $\left({ }^{* *}\right)$.
Table 3

Phenotypic Correlations between CBCL/4 - 18 Scales

\begin{tabular}{lccc}
\hline \multicolumn{4}{c}{ Externalizing } \\
Internalizing & .68 & & \\
& Anxious & Somatic & Withdrawn \\
Anxious & & .41 & .66 \\
Somatic & & & .43 \\
& Delinquent & Attention & Aggressive \\
Delinquent & & .58 & .71 \\
Attention & & & .69 \\
& Internalizing & Externalizing & \\
Attention & .62 & .70 & Withdrawn \\
& Anxious & Somatic & .54 \\
Attention & .58 & .36 &
\end{tabular}

Table 2 gives the parameter estimates for genetic and environmental influences for the scales and the two broadband groupings of the CBCL/4-18 from multivariate analyses.

For all primary scales, except Withdrawn, and the two broadband groupings, the genetic influences are statistically significant. With the exception of the Delinquent Behavior scale, the estimated variance components are similar to those reported by Edelbrock et al. (1995). Shared environmental influences did not reach statistical significance for the primary scales, again consistent with Edelbrock et al. (1995), but did for the broadband groupings. The parameter estimates for Intermalizing and Externalizing are similar to those reported by van der Falk et al. (submitted) for seven-year-old twins.

Table 3 presents the phenotypic correlations between scales of the CBCL/4-18. The first panel shows the correlation between the broadband groupings of Internalizing and Externalizing. The next two panels show the correlations within each domain, that is, between Anxious/Depressed, Somatic Complaints, and Withdrawn as the internalizing behaviors, and between Aggressive and Delinquent as the externalizing behaviors, with the addition of Attention Problems which is often regarded as another disruptive behavior. These correlations are similar for boys and girls, as well as for same versus opposite sex pairs. The last two panels take a closer look at the correlations across domains, exemplified by showing the correlations of Attention Problems with the two broadband groupings and with the three internalizing scales.

As expected, the correlations are moderate to high. The correlation of .68 between Internalizing and Externalizing is slightly higher than that reported for the norm sample by Achenbach (1991; $r=.55$ for boys, $r=.56$ for girls). Correlations within the internalizing domain seem to be lower than the externalizing ones, with the exception of the one between Anxious/Depressed and Withdrawn $(r=.66)$. Within the externalizing domain, correlations are generally high, as are those between Attention Problems and the two broadband groupings. The correlation between Delinquent and Aggressive Behaviors $(r=.71)$ is practically identical to that reported by Deater-Deckard and Plomin (1999; $r=$ .70). Associations between Attention Problems and the 
Table 4

Genetic Correlations between CBCL/4 - 18 Scales

\begin{tabular}{|c|c|c|c|}
\hline & Externalizing & & \\
\hline Internalizing & $.63(.46)^{*}$ & & \\
\hline $\begin{array}{l}\text { Anxious } \\
\text { Somatic }\end{array}$ & Anxious & $\begin{array}{c}\text { Somatic } \\
.26(.31)\end{array}$ & $\begin{array}{c}\text { Withdrawn } \\
.73(.41) \\
.50(.44)\end{array}$ \\
\hline $\begin{array}{l}\text { Delinquent } \\
\text { Attention }\end{array}$ & Delinquent & $\begin{array}{l}\text { Attention } \\
.65(.79)^{* * *}\end{array}$ & $\begin{array}{l}\text { Aggressive } \\
.78(.76)^{* * *} \\
.76(.70)^{* * *}\end{array}$ \\
\hline Attention & $\begin{array}{c}\text { Internalizing } \\
.73(.57)^{* *}\end{array}$ & $\begin{array}{c}\text { Externalizing } \\
.71(.56)^{* *}\end{array}$ & \\
\hline Attention & $\begin{array}{l}\text { Anxious } \\
.71(.65)^{* * *}\end{array}$ & $\begin{array}{l}\text { Somatic } \\
.16(.23)\end{array}$ & $\begin{array}{c}\text { Withdrawn } \\
.79(.54)^{*}\end{array}$ \\
\hline
\end{tabular}

primary internalizing scales are low for Somatic Complaints but fairly high for the other two scales and similar in magnitude to correlations between the other externalizing behaviors with the internalizing ones.

Looking at the etiology of the associations, Tables 4, 5, and 6 break down these phenotypic correlations into those parts due to genetic and those due to environmental influences. Two numbers are given for each correlation: the first gives the magnitude of a particular correlation that is indicative of the amount of genetic or environmental variance shared between two scales. The number in parentheses is scaled by the magnitude of the estimated variance component and thus gives the percentage of how much is contributed to the phenotypic correlation.

Genetic influences contribute substantially to the phenotypic correlations, particularly to those within the externalizing domain. Correlations between Attention Problems, Delinquent, and Aggressive are between 70 and $79 \%$ genetically mediated. Within the Internalizing domain, genetic factors only contribute between 31 and 44 percent of the correlation and are not significant with this sample size. The remaining genetic correlations are inter-

Table 5

Shared Environmetal Correlations between CBCL/4 - 18 Scales

\begin{tabular}{|c|c|c|c|}
\hline \multicolumn{3}{|c|}{ Externalizing } & \\
\hline Internalizing & $1.00(.44)^{*}$ & & \\
\hline $\begin{array}{l}\text { Anxious } \\
\text { Somatic }\end{array}$ & Anxious & $\begin{array}{l}\text { Somatic } \\
.99(.46)\end{array}$ & $\begin{array}{c}\text { Withdrawn } \\
.99(.37) \\
.99(.52)\end{array}$ \\
\hline $\begin{array}{l}\text { Delinquent } \\
\text { Attention }\end{array}$ & Delinquent & $\begin{array}{l}\text { Attention } \\
.99(.14)\end{array}$ & $\begin{array}{c}\text { Aggressive } \\
.99(.16) \\
.99(.17)\end{array}$ \\
\hline Attention & $\begin{array}{l}\text { Internalizing } \\
.99(.39)\end{array}$ & $\begin{array}{l}\text { Externalizing } \\
.99(.28)\end{array}$ & \\
\hline Withdrawn\Attentio & $\begin{array}{l}\text { Anxious } \\
1.00(.30)\end{array}$ & $\begin{array}{l}\text { Somatic } \\
.99(.46)\end{array}$ & $.99(.43)$ \\
\hline
\end{tabular}

mediate, ranging from 46 percent (Internalizing with Externalizing) to 65 percent (Attention Problems and Anxious/Depressed) of the phenotypic correlations, with the exception of Attention Problems with Somatic Complaints where the genetic correlation contributes only $23 \%$ of the observed correlation. Even though the observed correlations within and across domains were of similar magnitude, genetic factors seem to contribute a larger proportion towards correlations involving externalizing behaviors, including Attention Problems. The magnitude of the genetic correlations is slightly higher than those reported by van den Oord et al. (2000) for three-year-olds where genetic components contributed just under $40 \%$ to the phenotypic associations.

Table 5 shows that all the shared environmental variance is in common to all the scales in the analyses; however, since the amount of shared environmental variance differs between the scales, these environmental influences common to aspects of problem behavior contribute between only 14\% (Attention Problems and Delinquent) and 52\% (Somatic Complaints and Withdrawn) of the observed correlations. The estimated shared environmental correlations are either unity or close to it, meaning that there is only one set of environmental factors which are shared by the various aspects of problem behavior, replicating the results of van den Oord et al. (2000). They are non-significant with this sample size except for the correlation between Internalizing and Externalizing to which genetic and shared environmental factors contribute with similar amounts. Both genetic and shared environmental correlations are non-significant within the internalizing domain, meaning larger sample sizes are needed to resolve the significance of their contributions.

Lastly, correlations due to non-shared environmental factors are shown in Table 6.

Non-shared environmental factors contribute little to the observed correlation, meaning that these influences are specific to each behavior or due to measurement error. Interestingly, a few of these correlations are significant, namely those between Anxious and Withdrawn, Attention and Aggressive Problems, and Attention Problems and

\section{Table 6}

Non-Shared Environmental Correlations between CBCL/4 - 18 Scales

\begin{tabular}{|c|c|c|c|}
\hline & Externalizing & & \\
\hline Internalizing & $.21(.10)$ & & \\
\hline $\begin{array}{l}\text { Anxious } \\
\text { Somatic }\end{array}$ & Anxious & $\begin{array}{l}\text { Somatic } \\
.17(.23)\end{array}$ & $\begin{array}{c}\text { Withdrawn } \\
.28(.22)^{* *} \\
.26(., 04)\end{array}$ \\
\hline $\begin{array}{l}\text { Delinquent } \\
\text { Attention }\end{array}$ & Delinquent & $\begin{array}{l}\text { Attention } \\
.11(.07)\end{array}$ & $\begin{array}{c}\text { Aggressive } \\
.18(.08) \\
.25(.13)^{*}\end{array}$ \\
\hline Attention & $\begin{array}{c}\text { Internalizing } \\
.05(.04)\end{array}$ & $\begin{array}{l}\text { Externalizing } \\
.31(.15)^{* *}\end{array}$ & \\
\hline Attention & $\begin{array}{l}\text { Anxious } \\
.08(.06)\end{array}$ & $\begin{array}{l}\text { Somatic } \\
.19(.31)\end{array}$ & $\begin{array}{c}\text { Withdrawn } \\
.03(.03)\end{array}$ \\
\hline
\end{tabular}


Externalizing. Non-shared environmental correlations imply that they occur due to events that happen only to one twin of the pair, such as an accident or a serious illness, or due to individual impressions which provide an indication for intervention approaches based on the individual. In the Dutch sample of three-year-olds, non-shared environmental correlations contributed only about 11 to the observed correlations but showed more evidence of nonshared environmental factors common to a number of scales (van den Oord et al., 2000).

In summary, similar to O'Connor et al. (1998) and van den Oord et al. (2000), we found large significant associations between problem behaviors, both within and between domains, particularly the externalizing ones. Common shared environmental factors contributed to co-occurrences between problem behaviors but were non-significant which is in contrast to the findings reported by Gjone and Stevenson (1997). As expected, non-shared environmental factors contributed only to a few associations.

\section{Discussion}

This study showed that the often reported correlations between aspects of problem behavior were due to both genetic and shared environmental associations. Correlations within the externalizing domain were mainly due to genetic influences common to attention problems and aggressive as well as delinquent aspects of behavior; environmental influences contributed less to the observed correlations. Correlations between internalizing behaviors were equally influenced by common genetic and shared environmental influences. The high phenotypic and genetic correlations between Attention Problems and externalizing behaviors confirmed the choice to include this scale in the analyses with other disruptive behaviors of the externalizing domain.

Parameter estimates for genetic and environmental aspects of problem behavior were similar to those reported in the literature. Externalizing behaviors have been shown to be more genetically mediated from an early age on (Schmitz et al., 1994; van der Falk, submitted; van den Oord, 1993; van den Oord et al., 2000), making genetic correlations between behaviors in this domain plausible. The surprising result from this study was that, in contrast to Gjone and Stevenson (1997), even for children at this younger age, the associations between internalizing and externalizing behaviors were significantly genetically mediated as well. Similar to van den Oord et al. (2000), the shared environmental factor structure in our sample showed that one factor was responsible for these environmental influences but they were weaker than those in the Norwegian sample reported on by Gjone and Stevenson (1997).

Another unexpected result was the significance of some of the non-shared environmental correlations. Usually nonshared environmental factors, which include measurement error, are specific to either the measurement occasion or a particular aspect of behavior. However, same as in this sample, van den Oord et al. (2000) reported, even for three-year-old twins, some significant associations between problem behaviors due to non-shared environmental factors, meaning events happening to one twin only might contribute to these associations. Apart from replicating these findings, further research is needed into the nature of these factors which are not shared by the members of the twin pair, particularly why they were only seen for the above combinations of behaviors in our sample but for more in the Dutch sample. Also of importance would be the investigation of sibling interaction effects at different ages, for which the current data showed no evidence but which were statistically significant for some behavioral aspects in a large sample of twins (Eaves et al., 1997).

Most of the research in this area is based on maternal reports, due to the age of the children; the validity of mother ratings, particularly of internalizing behaviors, has been recognized. Rowe and Kandel (1997) reported that the trait component of parental ratings, that part which contains the shared parental view, accounted for 42 to $58 \%$ of the variation. Similarly, Hewitt et al. (1992) found components of problem behavior independent of parental rating biases.

A potential problem is that all problem behavior scales are correlated to varying degrees, making differential diagnostic decisions problematic; however, as the current analyses and those of others (van den Oord, 1993; van den Oord et al., 2000) show, there are differences in the extent to which genetic and environmental influences contribute to aspects of problem behavior whic $0 \mathrm{~h}$ leads van den Oord et al. (2000) to suggest a diagnostic system based on etiological differences, rather than phenotypic factor analyses.

This sample is a non-clinical population sample and results should not be generalized to children displaying extreme problem behavior. However, since the CBCL/4-18 as a continuous measure is appropriate for both clinical and non-clinical samples, it can be assumed that the correlations reported here will replicate in other populations. Obviously, more research is needed into the reported correlations between internalizing and externalizing behaviors (e.g., Biederman et al., 1996; Gabel et al., 1996) as well as the application of interventions.

\section{Acknowledgments}

This research was supported in part by a small grant from the John D. and Catherine T. MacArthur Foundation: Transition from Infancy to Childhood Network and a Graduate School Dean's Small Grant Award. S. S. was supported in part by Grant HD-07289 when the data were collected and currently by MH-62116. Part of these data were presented as a poster at the 1997 (Vth) World Congress of Psychiatric Genetics, Santa FE, NM, in October 1997. The authors wish to acknowledge the important role of the late Dr. David W. Fulker in initiating and continuing this project.

\section{References}

Achenbach, T. M. (1991). Manual for the Child Behavior Checklist/4-18 and 1991 Profile. Burlington, VT: University of Vermont, Department of Psychiatry.

August, G. J., Realmuto, G. M. \& MacDonald, A. (1996). Prevalence of ADHD and comorbid disorders among elementary school children screened for disruptive behavior. Journal of Abnormal Child Psychology, 24(5), 571-595. 
Biederman, J., Faraone, S., Mick, E., Wozniak, J., Chen, L., Ouellette, C., Marrs, A., Moore, P., Garcia, J., Mennin, D., \& Lelon, E. (1996). Attention-deficit hyperactivity disorder and juvenile mania: An overlooked comorbidity? Journal of the American Academy of Child and Adolescent Psychiatry, 35(8), 997-1008.

Deater-Deckard, K., \& Plomin, R. (1999). An adoption study of the etiology of teacher reports of externalizing problems in middle childhood: Comparing individual differences and extreme groups. Child Development, 70(1), 144-154.

Eaves, L. J., Silberg, J. L., Meyer, J. M., Maes, H. M., Simonoff, E., Pickles, A., Rutter, M., Neale, M. C., Reynolds, C. A., Erikson, M. T., Heath, A. C., Loeber, R., Truett, K. R., \& Hewitt, J. K. (1997). Genetics and developmental psychopathology: 2. The main effects of genes and environment on behavioral problems in the Virginia Twin Study of Adolescent Behavioral Development. Journal of Child Psychology and Psychiatry, 38(8), 965-980.

Edelbrock, C., Rende, R., Plomin, R., \& Thompson, L. A. (1995). A twin study of competence and problem behavior in childhood and early adolescence. Journal of Child Psychology and Psychiatry, 36, 775-785.

Eiraldi, R. B., Power, T. J., \& Nezu, C. M. (1997). Patterns of comorbidity with subtypes of AttentionDeficit/Hyperactivity Disorder among 6- to 12-year-old children. Journal of the American Academy of Child and Adolescent Psychiatry, 36(4), 503-514.

Eley, T. C. (1997). How multivariate behavioral genetic analyses can inform molecular genetics: Externalizing and internalizing behavior in young twins. American Journal of Medical Genetics (Neuropsychiatric Genetics), 74(6), 569(abstract).

Gabel, S., Schmitz, S., \& Fulker, D. W. (1996). Comorbidity in hyperactive children: Issues related to selection bias, gender, severity and internalizing symptoms. Child Psychiatry and Human Development, 27(1), 15-28.

Gjone, H., \& Stevenson, J. (1997). The association between internalizing and externalizing behavior in childhood and early adolescence: Genetic or environmental common influences? Journal of Abnormal Child Psychology, 25(4), 277-286.

Goldsmith, H. H. (1991). A zygosity questionnaire for young twins: A research note. Behavior Genetics, 21, 257-269.

Hewitt, J. K., Silberg, J. L., Neale, M. C., Eaves, L. J., \& Erickson, M. (1992). The analysis of parental ratings of children's behavior using LISREL. Behavior Genetics, 22, 293-317.

LaBuda, M. C., Gottesman, I. I., \& Pauls, D. L. (1993). Usefulness of twin studies for exploring the etiology of childhood and adolescent psychiatric disorders. American Journal of Medical Genetics (Neuropsychiatric Genetics), 48, 47-59.

Martin, N. G., Boomsma, D., \& Machin, G. (1997). A twinpronged attack on complex traits. Nature Genetics, $17,387-392$.

Neale, M. C. (1997). Mx: Statistical modeling (4th ed.). Medical College of Virginia: Department of Psychiatry.

Nichols, R. C., \& Bilbro, W. C. J. (1966). The diagnosis of twin zygosity. Acta Geneticae Statisticae Medicinae, 16, 265-275.

O'Connor, T. G., McGuire, S., Reiss, D., Hetherington, E. M., \& Plomin, R. (1998). Co-occurence of depressive symptoms and antisocial behavior in adolescence: A common genetic liability. Journal of Abnormal Psychology, 107(1), 27-37.

Rowe, D. C., \& Kandel, D. (1997). In the eye of the beholder? Parental ratings of externalizing and internalizing symptoms. Journal of Abnormal Child Psychology, 25(4), 265-275.

Rutter, M., Bolton, P., Harrington, R., Le Couteur, A., Macdonald, H., \& Simonoff, E. (1990). Genetic factors in child psychiatric disorders - I. A review of research strategies. Journal of Child Psychology and Psychiatry, 31, 3-37.

Schmitz, S., Cherny, S. S., Fulker, D. W., \& Mrazek, D. A. (1994). Genetic and environmental influences on early childhood behavior. Behavior Genetics, 24, 25-34.

Schmitz, S., Fulker, D. W., \& Mrazek, D. A. (1995). Problem behavior in early and middle childhood: An initial behavior genetic analysis. Journal of Child Psychology and Psychiatry, 36, 1443-1458.

Van den Oord, E. J. C. G. (1993). A genetic study of problem behavior in children. Unpublished doctoral dissertation, University of Rotterdam.

Van den Oord, E. J. C. G., Boosma, D. I., \& Verhulst, F. C. (2000). A study of genetic and environmental effects on the co-occurrence of problem behaviors in three-year-old twins. Journal of Abnormal Psychology, 109(3), 360-372.

Van der Falk, J. C., Van den Oord, E. J. C. G., Verhulst, F. C., \& Boomsma, D. I. (submitted). Using common and unique parental views to study the etiology of seven-year-old twins' Internalizing and Externalizing problems. 